Running head: ESSENTIALISM PROMOTES AND MITIGATES PREJUDICE

Why does social essentialism sometimes promote, and other times mitigate, prejudice development? A causal discounting perspective

\author{
Rebecca Peretz-Lange \\ Boston University
}

Word count: 6,220

Corresponding author:

Rebecca Peretz-Lange, Ph.D.

rebpl@,bu.edu 


\begin{abstract}
Children often hold "essentialist" intuitions about social categories, viewing them as reflecting people's intrinsic essences or biological natures. This intuition promotes prejudice development (e.g., race- and gender-based prejudices). However, emerging research reveals that essentialism also mitigates prejudice development (e.g., weight- and sexuality-based prejudices). Why do children's essentialist views sometimes promote prejudice, and other times mitigate it? I propose that causal discounting may account for these distinct effects: Essentialism may promote prejudice by leading children to discount structural explanations (i.e., to reason that a group is low-status because of its personal deficiencies rather than its structural disadvantages), but it may mitigate prejudice by leading children to discount agentic explanations (i.e., to reason that a group was "born that way" rather than choosing to be that way). Thus, the consequences of essentialism may reflect both the explanations children endorse as well as those they discount. Cognitive, developmental, and social implications are discussed.
\end{abstract}

Keywords: Social essentialism, causal reasoning, causal discounting, explanations, prejudice, development, explanations 


\section{Why does social essentialism sometimes promote, and other times mitigate, prejudice development? A causal discounting perspective}

Children hold "essentialist" intuitions about social categories from a young age, viewing such categories as natural and assuming that category members share a deep underlying "essence" that accounts for their similarities (Gelman, 2003). These early essentialist intuitions play a critical role in the development of prejudice, or negative group-based attitudes (Dovidio et al., 2010). To date, most discussion has focused on how social essentialism promotes prejudice development. For example, social essentialism has been widely shown to promote early prejudices based on race, ethnicity, and gender (see Rhodes \& Mandalaywala, 2017 for a review). However, emerging research on understudied forms of prejudice shows that social essentialism can sometimes mitigate children's prejudices as well. For example, essentialist views reduce children's prejudices based on weight, sexual orientation, and incarceration status compared to children's prejudices at baseline (Carvalho et al., 2021; Dunlea \& Heiphetz, 2020; Horn, 2019). Why do children's essentialist views sometimes promote prejudice, and other times mitigate it?

To address this question, I first review work on the prejudice-promoting and prejudicemitigating effects of social essentialism in childhood, focusing especially on the cognitive mechanisms underlying each effect. I then propose that causal discounting may account for why essentialism sometimes promotes and other times mitigates prejudice development. Causal discounting involves automatically viewing alternative causal explanations as less likely when a given causal explanation (e.g., an essentialist explanation) is viewed as more likely (Gopnik et al., 2001; Newman \& Ruble, 1992). Essentialism may promote prejudice by leading children to 
discount structural explanations (i.e., by leading children to infer that a group is low-status because of its essential deficiencies, rather than its structural disadvantages), but it may mitigate prejudice by leading children to discount agentic explanations (i.e., by leading children to infer that a group was "born that way," rather than choosing to be that way). In other words, the consequences of essentialist reasoning may be a function not only the explanations children endorse, but also of the explanations children discount. Finally, I discuss some developmental implications of this framework and highlight some directions for future cognitive developmental research.

\section{Social essentialism}

"Social essentialism" refers to an early-developing intuitive theory about social categories. Primarily, it refers to the intuition that members of a social category share an unobservable intrinsic "essence" that determines their category membership and gives rise to their observable similarities (Gelman, 2003). Social essentialism also comprises a web of related intuitive beliefs about social categories, including a belief in the heritability of social category membership (Diesendruck, Birnbaum, Deeb, \& Segall, 2013; Gelman, Heyman, \& Legare, 2007), a belief in the stability of a person's social category membership across their lifespan (Pauker, Ambady, \& Apfelbaum. 2010), a belief that social categories are objective rather than constructed (Diesendruck et al., 2013), a belief that social category boundaries are sharp rather than graded (Gaither et al., 2014; Roberts, Ho, Rhodes, \& Gelman, 2017), and a belief that social category members are similar to one another and different from members of other categories (Diesendruck \& HaLevi, 2006; Diesendruck \& Menahem, 2015; Gelman et al., 1986). Here, I primarily focus on the essentialist view that category membership and category members' shared 
properties are caused by some kind of internal "essence" (Gelman \& Wellman, 1991). This may be a conceptually central and early-emerging component of essentialist theories (Cimpian \& Salomon, 2014; Cimpian \& Steinberg, 2014; Sutherland \& Cimpian, 2019) with particularly strong links to prejudice (Mandalaywala et al., 2019).

Children apply their essentialist intuitions to a wide variety of social categories, including gender (Gelman \& Taylor, 2000; Gelman, Taylor, \& Nguyen, 2004; Taylor, Rhodes, \& Gelman, 2009), race (Hirschfeld, 2008; Mandalaywala, et al., 2018; Pauker, Ambady, \& Apfelbaum, 2010; Roberts \& Gelman, 2016), ethnicity (Deeb et al., 2011; Diesendruck \& Menahem, 2015; Segall, et al., 2015) spoken language (Dautel \& Kinzler, 2018; Kinzler \& Dautel, 2012), religion (Chalik, Leslie, \& Rhodes, 2017; Heiphetz, Gelman, \& Young, 2017; Smyth et al., 2017), and nationality (Davoodi et al., 2020; Feeney et al., 2020; Hussak \& Cimpian, 2019). Children's endorsement of essentialism varies across these different social categories (Davoodi et al., 2020), reflecting the fact that their essentialist views are triggered or amplified by the varying linguistic cues, social inputs, and cultural messages that children receive about different social categories (Diesendruck et al., 2013; Pauker et al., 2016; Rhodes, Leslie, \& Tworek, 2012).

\section{Prejudice-promoting consequences of social essentialism}

Social essentialism has been widely shown to promote prejudice based on race, ethnicity, and gender, among both children and adults (see Rhodes \& Mandalaywala, 2017 for a review). Essentialist views shape many aspects of prejudice; for example, essentialist reasoning impacts children's and adults' implicit and explicit attitudes (Diesendruck \& Menahem, 2015; Hussak \& Cimpian, 2015; Mandalaywala, Amodio, \& Rhodes, 2018; Williams \& Eberhardt, 2008), promotes children's and adults' stereotype endorsement (Bastian \& Haslam, 2006; Pauker et al., 
2010; Taylor, Rhodes, \& Gelman, 2009), reduces children's and adults' desire to interact with outgroup members (Bernstein et al., 2010; Levy \& Dweck, 1999; Williams \& Eberhardt, 2008), and leads children and adults to ignore those at the margins of social category membership (e.g., those who are racially ambiguous, Gaither et al., 2014; Roberts, Ho, Rhodes, \& Gelman, 2017).

These impacts of essentialism on prejudice likely reflect several distinct mechanisms. As reviewed above, social essentialism encompasses a variety of different component beliefs, including a belief in intrinsic causal essence, belief in the heritability and stability of category membership, belief in the similarity of category members, and and a belief in categories' objectivity and sharp boundaries. These beliefs may all contribute differently to prejudice. For example, a belief in stability of category membership may promote stereotyping, especially toward low-status groups (Pauker et al., 2010), and a belief in within-group similarity may lead children to view category members as more similar to one another and more different from members of other categories (Diesendruck \& Menahem, 2015). Thus, there are multiple mechanisms underlying the relation between essentialism and prejudice.

One prominent mechanism by which social essentialism promotes prejudice is by shaping people's explanations for social status disparities (Allport, 1954). For example, Williams and Eberhardt (2008) assigned adult participants to read a fictional scientific article that provided an explanation for racial disparities. Some participants read an article purportedly from journal Gene which attributed racial disparities to genetic differences between races, while others read an article purportedly from the New York Times which attributed these disparities to structural barriers facing Black men. They found that the genetic essentialism article increased acceptance of disparities and reduced people's desire to interact with racial outgroup members. Demonstrating the importance of reasoning about status in this process, Mandalaywala, Amodio, 
and Rhodes (2018) found that the impacts of racial essentialism on adults' racial prejudice (including explicit prejudice, implicit prejudice, and group-based affect assessed using a "feelings thermometer") were mediated by the endorsement of racial status hierarchies. Thus, essentialism promotes prejudice in part by shaping people's reasoning about status disparities.

Children also hold prejudices toward low-status groups. By the preschool years, children are aware of intergroup disparities in material wealth (e.g., having a nice house, Olson et al., 2012; Shutts et al., 2016), social power (e.g., making decisions, Gülgöz \& Gelman, 2017; Mandalaywala, Tai, \& Rhodes, 2020), and social dominance (e.g., being “on top” of a hierarchy, Thomas et al., 2018). Across cultures, children prefer high- over low-status groups (England: Davey, 1983; Taiwan: Kowalski \& Lo, 2001; South Africa: Shutts et al., 2011), even when these groups are novel and fictional (Bigler, Brown, \& Markell, 2001; Nesdale \& Flesser, 2001). Children of diverse backgrounds, including those from low-status backgrounds themselves, incorporate status disparities into their social attitudes (Dunham et al., 2014; Olson et al., 2012; Shutts et al., 2011).

Essentialism promotes children's prejudices toward low-status groups (see Elenbaas, Rizzo, \& Killen, 2020 for a review), with essentialist explanations for status disparities playing a particularly prominent role in this process. Mandalaywala and colleagues (2019) assessed three components of racial essentialism in White and Black children: their beliefs in racial stability, heritability, and an intrinsic causal essence. The only measure that predicted prejudice toward low-status racial groups was the belief that race was tied to a causally powerful intrinsic essence. Belief in an intrinsic causal essence predicted reduced liking of Black children, among both White and Black participants. Thus, although essentialism is a multifaceted construct, the 
attributional component of essentialism - the belief that a group's characteristics are explained by an intrinsic essence - appears to play a prominent role in prejudice development.

Children's essentialist explanations for social status disparities may even drive the initial formation of prejudice, according to studies utilizing novel group paradigms. For example, Hussak and Cimpian (2015) taught preschoolers about novel social categories (e.g., Blarks and Orps on the planet Teeku) and presented with different social status disparities (e.g., "the Blarks have a lot more money than the Orps"). Children were then provided with an explanation for this disparity, either an essentialist explanation referencing intrinsic causes (e.g., "Maybe the Blarks are smarter ... or there's something else about them") or a structural explanation referencing extrinsic causes (e.g., "Maybe the Blarks ... found gold or something else happened a long time ago") in a counterbalanced order. They found that participants agreed more strongly with the essentialist explanations overall, and that participants' agreement with each explanation predicted their liking of each group and their endorsement of the status disparity. In follow-up studies, the researchers confirmed that manipulating participants' explanations for the status disparities also impacted these outcomes directionally. In another study, Peretz-Lange, Perry, and Muentener (2021) told children (five- and six-year-olds as well as nine- and ten-year-olds) about social status disparities between various novel groups, such as the Reds being dominant over the Greens. Participants were familiarized with a plausible intrinsic cause and a plausible extrinsic cause of each disparity, which were equally salient and presented in a counterbalanced order. The disparities were verbally framed to highlight either the intrinsic cause, the extrinsic cause, or neither. They found that, although children tended to provide mostly essentialist explanations overall (e.g., explanations citing a group’s biological nature or innate abilities), verbally highlighting extrinsic causes led children to provide more structural explanations. In 
turn, children's explanations predicted their social preferences, with essentialist explanations predicting preferences for the high- over the low-status groups, and structural explanations predicting no such preference, among both preschoolers and older children. Notably, studies manipulating essentialism of novel groups without including information about groups' status have found no impacts on children's attitudes (e.g., Rhodes et al., 2018), in line with the idea that essentialism shapes children's attitudes largely by shaping their explanations for social status disparities (see Rhodes \& Mandalaywala, 2017 for a discussion).

In sum, social essentialism often promotes prejudice toward low-status groups. In particular, one mechanism by which it does so is through coloring children's and adults' explanations for social status disparities, portraying these disparities as reflecting groups' intrinsic superiority/inferiority rather than their extrinsic advantages/disadvantages. Note that, although the reviewed studies focus on the consequences of augmenting the likelihood of essentialist explanations for social disparities, these consequences may also reflect children having discounted the likelihood of alternative, structural explanations for disparities.

\section{Prejudice-mitigating consequences of social essentialism}

Recent reviews of social essentialism in childhood have focused primarily on its negative effects (Rhodes \& Mandalaywala, 2017), accurately capturing the literature at the time and the dominant view of essentialism as socially problematic. However, research with adults has identified some forms of prejudice that are instead mitigated by social essentialism, such as prejudice based on weight (Diedrichs \& Barlow, 2011; Monterosso et al., 2005; Puhl et al., 2005; Teachman et al., 2003), sexual orientation (Haslam \& Levy, 2006; Hegarty \& Pratto, 2001; Jayaratne et al., 2006; Whitley, 1990), mental illness (Angermeyer \& Matschinger, 2004; Baker 
\& Menken, 2001; Lebowitz, Rosenthal, \& Ahn, 2016), and engagement in criminal behavior (Dar-Nimrod et al., 2010; Monterrosso, Royzman, \& Schwartz, 2005). ${ }^{1}$

Recently, research has begun to capture prejudice-mitigating consequences of social essentialism among children as well. For example, Carvalho, Peretz-Lange, and Muentener (2021) found that biological-essentialist views of weight mitigate children's weight biases, which are robust (see Puhl \& Latner, 2007 for a review). The researchers presented four- to elevenyear-old children either a biological explanation for weight ("because of how that body is built" and "how their body works"), a behavioral explanation ("because of what that person is eating [and] how much they're exercising"), or neither. They then presented participants with a series of pairs of children of different weights and asked participants whom they would prefer to play with. Although children tended to prefer the thin playmate overall, receiving biological explanations mitigated this preference. Moreover, behavioral explanations exacerbated this preference, making children even more likely to choose the thin playmate. These experimental results build upon correlational findings that children's beliefs about the behavioral controllability of weight predict their weight biases (Musher-Eizenman et al., 2004; Tiggeman \& Anesbury, 2000). Thus, essentialist explanations - those attributing someone's weight to their internal biology - mitigate weight bias in childhood, as in adulthood.

Emerging research also suggests that children's essentialist views of homosexuality predict reduced prejudice toward LGBTQ people. Spence, Helwig and Cosentino (2018) assessed seven- to fourteen-year-old children's essentialist conceptions of same-sex attraction by asking them about the likelihood of various explanations for same-sex attraction and about

\footnotetext{
${ }^{1}$ Note, however, that essentialist explanations for criminal behaviors can also increase punitive responses to these behaviors (de Vel-Palumbo, Howarth, \& Brewer, 2019; Kraus \& Keltner, 2013; Martin \& Heiphetz, 2021). The nuanced impacts of essentialism in this domain are later discussed in more depth.
} 
whether a person could change their mind and decide to prefer other-sex partners. They also assessed children's anti-gay judgments, such as their views of whether same-sex relationships are "okay" and whether it is acceptable to socially exclude gays and lesbians. They found that, with age, children grew more likely to believe that homosexuality had a biological basis and to view it as immutable, and that this shift in conceptions corresponded with developmental declines in anti-gay judgments. The authors reasoned that older children entering puberty may have personal experiences with attraction as reflecting hormones or biological urges; in contrast, younger children lack personal experience in this domain and may construe romantic preferences as more akin to personal opinions, which they do not strongly essentialize (Heiphetz, Gelman, \& Young, 2017). In another line of work, Horn and Heinze (2011) asked over 1,000 adolescents to choose among a variety of statements about the origins of homosexuality, including statements referencing biological explanations, choice, and parental socialization. They found that adolescents who endorsed biological explanations viewed homosexuality as less wrong and reported being more comfortable interacting with lesbian and gay peers (for similar findings, see Horn, 2006; Turiel et al., 1991). Although these findings are correlational in nature, they mirror experimental findings from adults. Indeed, a recent review article concluded that beliefs about the origins and causes of sexual orientation play an important role in the development of anti-gay prejudice (Horn, 2019).

Researchers have also begun to explore children's explanations for why people experience incarceration and how these explanations shape prejudice. Children, moreso than adults, tend to attribute incarceration to people's moral character (Dunlea \& Heiphetz, 2020). To explore how alternative explanations inform children's attitudes, Dunlea and Heiphetz (2020) provided six- to eight-year-old children with various explanations for why a person was 
incarcerated. They found that, compared to explanations referencing a person's moral character, explanations referencing a person's internal biology improved children's liking of the person described, as well as children's willingness to live near them. Supporting the idea that these effects reflecting conceptions of blame in particular, explanations referencing a person's upbringing also improved children's attitudes relative to character-related explanations (see Heiphetz, 2019 for additional evidence on this point).

Essentialist thinking may also improve children's attitudes toward those with mental illness. Following attributional theories of mental health stigma (Corrigan, 2000), Watson and colleagues (2004) arranged for 1,500 middle schoolers to receive a curriculum focused on the biological causal origins of mental illness. The curriculum focused on mental illness as an illness of the brain that is responsive to medication. Pre- and post-tests revealed that the curriculum improved children's understanding of the biological origins of mental illness, and in turn, children's attitudes toward those with mental illnesses (e.g., their views that mentally ill people are dangerous or should be locked away). However, research has not yet investigated how young children's explanations for mental illness impact their attitudes.

In sum, in contrast to prevailing views of essentialism as socially pernicious, social essentialist views in fact mitigate certain forms of prejudice. In these cases, essentialism leads children and adults to view people as "born that way" and to be less inclined to blame people for holding a stigmatized identity.

It is important to note that these prejudice-mitigating effects of essentialism are predicated upon children already viewing these identities as blameworthy. In other words, viewing someone's weight or sexual orientation as biologically-determined and out of their control should have no impact on one's attitudes unless one already views certain weights or 
sexual orientations as bad. It is not yet clear how children acquire a view of these identities as blameworthy from such a young age; this is a question future research should explore. Improving attitudes by portraying these identities as "not someone's fault" does not effectively promote acceptance of these identities themselves, and perhaps these effects do not even qualify as true prejudice-mitigation. However, the demonstrated social benefits of essentialist views (increased willingness to play with someone overweight, to socially include an LGBTQ peer, and to live near someone who has experienced incarceration) are nevertheless tangibly helpful to these communities. Moreover, although they are not the focus of this manuscript, there are other mechanisms by which essentialism may more meaningfully mitigate prejudice, such as by portraying identities as natural. Essentialism may trigger the "naturalistic fallacy," or the idea that phenomena (and identities) that are natural are morally acceptable (see discussion in DarNimrod et al., 2011). This fallacy does not involve perceptions of blame or controllability; for example, it is the fallacy involved in people's aversion to genetically modified organisms (GMOs). Indeed, essentialism has historically played a helpful role in identity-acceptance movements (see Mandalaywala, 2020 for a discussion). Overall, the prejudice-mitigating effects of essentialism leave something to be desired and raise further questions about how and why children view certain identities as blameworthy. Nevertheless, I view these prejudice-mitigating effects as underdiscussed and argue that they add important nuance to discussions of the social impacts of essentialism.

\section{A causal discounting approach to understanding the consequences of social essentialism}

So, why do children's essentialist views sometimes promote prejudice (e.g., in the domains of race, ethnicity, and gender), and other times mitigate it (e.g., in the domains of 
weight, sexual orientation, and incarceration status)? Past reviews of social essentialism have generally not engaged with this question. For example, some have described these diverse effects of essentialism on prejudice as representing a "mixed verdict" on whether essentialism promotes prejudice (Haslam, Rothschild, \& Ernst, 2002), rather than as a systematic pattern in how essentialism impacts different forms of prejudice. Others have positioned prejudice-mitigating findings as exceptions to the prejudice-promoting rule, while thoughtfully noting that essentialism has strong theoretical potential to be socially helpful (Mandalaywala, 2020). Still others have simply not discussed prejudice-mitigating effects of essentialism at all (Rhodes \& Mandalaywala, 2017). Instead, I view the diverse consequences of essentialism as an opportunity to better understand the cognitive mechanisms involved in essentialism-prejudice relations.

In particular, I propose that causal discounting can account for why essentialist views sometimes promote prejudice and other times mitigate it (Kelley, 1971) ${ }^{2}$. Causal discounting refers to the following process: In revising their causal models of the world, children weigh the perceived likelihoods of multiple candidate causal explanations (see Gopnik et al., 2004 for a review). When new evidence leads children to augment the perceived likelihood of one candidate causal explanation, it also leads them to discount the perceived likelihood of alternative causal explanations (Ali et al., 2010; Gopnik et al., 2001, Gopnik et al., 2004; Jaswal, 2010). Children engage in causal discounting when reasoning about the causes of physical events (Gopnik et al., 2001), of social behavior (Seiver, Gopnik, \& Goodman, 2013), and even of their own behavior (Newman \& Ruble, 1992). Critically, when reasoning about social groups, the alternative causal explanations children consider and discount may differ across social domains (e.g., race, weight),

\footnotetext{
${ }^{2}$ Note that causal discounting is unrelated to processes by which people update their perceived value of a reward, such as temporal discounting (Green, Myerson, \& McFadden, 1997) and hyperbolic discounting (Ainslie \& Haslam, 1992). However, all of these processes involve reducing a represented likelihood or value.
} 
and these domain differences can account for the different ways that essentialism impacts prejudice.

As reviewed above, the explanations being discounted differ across domains, contributing to the prejudice-promoting and -mitigating effects of essentialism (see Table 1). Essentialism promotes prejudice in part by leading children to discount structural explanations. It leads children to infer that a group is low-status because of their essential deficiencies, rather than their structural disadvantages. This pathway involves attributions for observed status disparities. In contrast, essentialism mitigates prejudice by leading children to discount what I refer to as agentic explanations, or explanations focused on freely-chosen behaviors. It leads children to infer that a group was "born that way," rather than choosing to be that way. This pathway involves attributions for identities that are viewed as blameworthy and potentially in one's control. Thus, there is a systematic difference in the mechanisms underlying prejudice-promoting and -mitigating effects of essentialism. The consequences of essentialist reasoning be a function not only the explanations children endorse, but also of the explanations they discount.

Table 1. Overview of domain differences in prejudice-promoting and-mitigating effects of essentialism.

\begin{tabular}{|l|l|l|}
\hline & $\begin{array}{l}\text { Prejudice-promoting effects of } \\
\text { essentialism }\end{array}$ & $\begin{array}{l}\text { Prejudice-mitigating effects of } \\
\text { essentialism }\end{array}$ \\
\hline Domains & Race, ethnicity, gender & $\begin{array}{l}\text { Weight, sexual orientation, mental } \\
\text { health, incarceration status*, } \\
\text { disability* }\end{array}$ \\
\hline $\begin{array}{l}\text { Explananda (features } \\
\text { being explained) }\end{array}$ & Social status disparities & Identities \\
\hline Alternative explanation & Structural explanation & Agentic explanation \\
\hline $\begin{array}{l}\text { Essentialist conclusion, } \\
\text { including the } \\
\text { discounted alternative } \\
\text { explanation }\end{array}$ & $\begin{array}{l}\text { They are in that position } \\
\text { because they are intrinsically } \\
\text { superior/inferior, rather than } \\
\text { because they are extrinsically } \\
\text { advantaged/disadvantaged }\end{array}$ & $\begin{array}{l}\text { They hold that identity because of } \\
\text { the way they were born, rather } \\
\text { than because they are choosing to } \\
\text { be that way }\end{array}$ \\
\hline
\end{tabular}

* For these identities, which are both low-status and viewed as blameworthy, both structural and agentic explanations are plausible. In these cases, essentialism mitigates prejudice relative to agentic explanations, but also promotes prejudice relative to structural explanations. 
To put this argument differently: If the alternative explanations being discounted are what account for the effects of essentialist reasoning, then we would expect the effects of essentialist reasoning to differ across domains where different alternative explanations are possible. This is exactly what the reviewed findings illustrate. Moreover, if domain differences in alternative explanations account for domain differences in consequences of essentialism, then promoting these alternative explanations should produce the opposite effects. Indeed, research suggests that in domains where essentialism promotes prejudice, structural explanations reduce prejudice (e.g., Hussak \& Cimpian, 2015; Peretz-Lange et al., 2021). In domains where essentialism mitigates prejudice, agentic explanations promote prejudice (e.g., Carvalho, Peretz-Lange, \& Muentener, 2021; Spence, Helwig, \& Cosentino, 2018).

Thus, domain differences in the consequences of essentialism are not a function of the domains themselves, but rather a function of which prior alternative explanations are entertained, and subsequently discounted, each domain: In domains such as race and gender, children's candidate hypotheses may include essentialist hypotheses and, to a lesser extent, structural hypotheses, but agentic hypothesis are not so plausible in these cases. For example, a child might wonder whether a low-status racial group is intrinsically inferior or extrinsically disadvantaged, but the possibility that that a group is choosing to be low-status is less plausible. In domains such as weight and sexual orientation, children's candidate hypotheses may include essentialist hypotheses and agentic hypotheses, but structural hypotheses are less plausible in these cases. For example, a child might wonder whether a person was born gay or is choosing to be gay, but the possibility that someone was made to be gay is less plausible. Support for this possibility emerges from experiments that include a control condition capturing children's causal theories at baseline. Even in these designs, essentialism leads to more positive attitudes than the control 
condition in some domains (e.g., weight, Carvalho et al., 2021) and less positive attitudes than the control condition in other domains (e.g., novel status disparities, Hussak \& Cimpian, 2015). These results suggest that children may hold different causal theories in different domains at baseline; as a result, promoting essentialism leads to children to discount different prior causal hypotheses across different domains.

These domain differences in alternative explanations may be related to domain differences in explananda (see Table 1). In the domains of race, ethnicity, and gender, the phenomenon being explained is why one group occupies a higher- or lower-status social position than another group. (Children may also use essentialist reasoning to explain why a person has a given race, ethnicity or gender in the first place, but here I focus on essentialist reasoning about status disparities, for which structural explanations represent an alternative account.) In these domains, inferences of intrinsic inferiority promote prejudice, and this is why inferences of extrinsic disadvantage mitigate prejudice. In contrast, in the domains of weight, sexual orientation, criminality, and mental illness, the phenomenon being explained is why people hold a certain identity in the first place. In these domains, identities are viewed as blameworthy in and of themselves, not merely because of their low social position. In these domains, inferences of blame promote prejudice, and this is why inferences of biological determinism mitigate prejudice. By the same logic, inferences of structural determinism also often mitigate prejudice toward these identities (Dunlea \& Heiphetz, 2020; though see Spence et al., 2018 for evidence that upbringing-related explanations for homosexuality do not effectively mitigate anti-gay attitudes).

Further evidence that distinction between prejudice-promoting and -mitigating effects is not a function of the identity itself, but rather a function of the alternative explanation being 
discounted, comes from research on prejudice toward identities that are both low-status and viewed as inherently blameworthy, for which all three explanations - essentialist, structural, and agentic - are plausible. According to the presented proposal, the low-status nature of these identities should make structural explanations prejudice-mitigating relative to essentialist explanations. Meanwhile, the blameworthy and potentially-chosen nature of these identities should make agentic explanations prejudice-enhancing relative to essentialist explanations. As such, we should expect structural explanations to foster the most positive attitudes, followed by essentialist explanations, followed by agentic explanations. Indeed, several lines of research reveal exactly this pattern. For example, when considering different physical conditions with different causal origins, children hold the most positive attitudes toward conditions reflecting an external cause (e.g., a child in crutches and a cast), followed by conditions reflecting one's inborn nature (e.g., a child with facial disfigurement), followed by conditions potentially reflecting one's behaviors (e.g., a child who is obese), an order of preferences found consistently in children across several cultures (Goodman et al., 1963; Koroni et al., 2009; Latner \& Stunkard, 2003; Richardson et al., 1961). Supporting the argument that these attitudes reflect the causal origins of each disability in particular, adults hold more positive attitudes toward those with acquired disabilities (i.e., those reflecting an accident) compared to those with congenital disabilities (i.e., those present since birth), even when the disability in question is controlled-for (Bogart, Rosa, \& Slepian, 2019). In addition to disability, incarceration status is another example of an identity for which all three explanations are possible. Once again, experimentally manipulating explanations for incarceration reveals that children hold the most positive attitudes toward those portrayed as incarcerated because of their circumstances or upbringing (a structural explanation), followed by those portrayed as incarcerated because of their biological nature (an 
essentialist explanation), followed finally by those portrayed as incarcerated because of their choices (an agentic explanation). ${ }^{3}$

In sum, I propose the consequences of essentialist explanations differ across domains because of domain differences in the alternative explanations children discount. The explanations that are discounted may vary depending on the domain and the phenomenon being explained. This framework leverages findings that had previously been viewed as inconsistent and uses them to shed new light on underlying cognitive processes.

\section{Developmental implications of the causal discounting approach}

Although causal discounting may account for the prejudice-promoting and -mitigating effects among both children and adults, these processes are especially important to explore in childhood when causal theories are still taking shape. Early causal learning is driven by several implicit and explicit processes, which the present framework suggests might be relevant for prejudice development.

Implicit statistical learning processes contribute to children's evaluation of different causal hypotheses. Children integrate observed covariation patterns (Seiver, Gopnik, \& Goodman, 2013; Schulz, Bonawitz, \& Griffiths, 2007; Sobel \& Kirkham, 2006) with their prior beliefs about the plausibility of a given cause (Fugelsang \& Thompson, 2001) to evaluate the likelihood of a given causal explanation. For example, children might observe that people's grades in school more reliably covary with their backgrounds rather than with their races, and integrate that information with their prior essentialist beliefs about race in order to determine whether structural or essentialist causes better explain observed racial disparities in achievement.

\footnotetext{
${ }^{3}$ Note that attitudes are actually most negative toward those whose incarceration reflects their moral character (Dunlea \& Heiphetz, 2020), a causal explanation not discussed in this manuscript.
} 
In addition to learning implicitly based on first-hand observations, children also learn about causal relations explicitly from those around them, such as through informal parent-child conversations (Chalik \& Rhodes, 2015). For example, parents might share information that contradicts children's prior causal-explanatory theories. This has been shown to prompt theory revision, especially when this new evidence is paired with an alternative causal-explanatory theory that could better account for this discrepant information (Ganea et al., 2020). When children receive explanatory information that contradicts their original beliefs, they weigh the strength of the evidence behind their original beliefs against the confidence, reliability, and knowledge of the informant to guide their conclusions (Bridgers et al., 2016; Sobel \& Kushnir, 2013; Tenney et al., 2011). The type of information provided also matters; children prefer mechanistic explanations to equally detailed non-mechanistic explanations, a preference which increases over development (Lockhart et al., 2019). Given the causal discounting proposal laid out here, these findings about children's causal learning are directly relevant for prejudice development. For example, parents may be an especially trustworthy source of counterintuitive explanatory information (e.g., structural explanations) for children. However, the types of explanations children receive for social status disparities may be more or less mechanistic across households, depending on parents' own understanding of mechanisms driving social disparities and the extent to which such topics are discussed at home (Bañales et al., 2020; Flanagan et al., 2014).

Children also exhibit developmental shifts in the domain-specificity of their causal theories which have implications for prejudice development. The present proposal suggests that, in order to form fewer prejudiced attitudes overall, children must discount essentialist causal theories in some domains (e.g., race) while maintaining them in others (e.g., weight). However, 
as causal learning is a domain-general process, children may generalize their understanding of causal relations in one domain to another domain (Schultz, Bonawitz, \& Griffiths, 2007). Domain-specific causal learning about essentialism may be especially challenging earlier in development, as younger children's essentialist theories are less differentiated across different domains compared to older children's. For example, Davoodi and colleagues assessed five- to ten-year-old children's essentialist beliefs about several different social domains (gender, nationality, religion, socioeconomic status, and sports team allegiance). Across both of the cultures studied, the researchers found that five-year-olds held essentialist theories in all five domains, but that their theories in each domain diverged over development. As they grew older, children grew to view gender in the most essentialist terms and sports team allegiance in the least essentialist terms.

Although causal theories become increasingly differentiated over development, even young children are capable of understanding that different causal mechanisms underlie different domains (Erickson, Keil, \& Lockhart, 2010; Smith \& Williams, 2004). For example, Smith and Williams (2004) asked four- to eleven-year-old children to rate their endorsement of different explanations for different disabilities. They found that even preschoolers most strongly endorsed biological explanations (e.g., "because he was born that way”) for blindness, physical trauma explanations (e.g., "because he fell") for being in a wheelchair, head injury explanations (e.g., "because he hit his head") for a learning disability, and unfortunately, intention explanations (e.g., "because he wants to be like that") for ADHD. However, younger children also endorsed biological explanations more strongly across the board than older children did, indicating that domain-general declines in essentialist reasoning also took place. Future research should explore how children's domain-general causal theories, and their capacity to generalize causal learning 
across domains, might complicate their ability to form the domain-specific causal theories necessary to reduce prejudice across domains.

\section{Future directions}

The causal discounting framework presented here motivates a variety of fruitful directions for future research. Most broadly, this framework suggests that engaging with the diverse effects of essentialism on prejudice will be fruitful for cognitive development research. Future work should examine essentialism-prejudice relations across a wider variety of social domains as an opportunity to better understand underlying cognitive mechanisms. In particular, within-subjects evidence that the same essentialist explanations yield different effects across different domains would strongly support the idea that essentialism both promotes and mitigates prejudice, and could elucidate the domain-related factors (e.g., group status, identity controllability, features being explained) that may account for these effects.

Although the reviewed research offers broad indirect support for the proposal that domain differences in the consequences of essentialism reflect domain differences in the alternative theories being discounted, future research should gather more direct support for this proposal. For example, researchers could assess children's baseline essentialist, structural, and agentic theories of a given social phenomenon before experimentally manipulating children's explanations. The causal discounting framework would predict that manipulations' impacts should depend on children's prior theories. Researchers should also investigate the extent to which these impacts generalize across domains, and whether such generalizations vary over development as children's causal theories become increasingly domain-specific. 
Next, although novel group paradigms have been used to investigate the prejudicepromoting consequences of essentialism (e.g., Hussak \& Cimpian, 2015; Peretz-Lange et al. 2021; Rhodes et al., 2018), these paradigms have not been used to investigate the prejudicemitigating consequences of essentialism. Future research should use novel group methods to investigate the circumstances under which essentialism mitigates prejudice. For example, researchers could create novel identities and teach children that the identities are (or are not) viewed as blameworthy, or that holding such an identity is (or is not) within one's control. According to this causal discounting framework, providing children with essentialist explanations for a blameworthy, controllable identity should mitigate prejudice toward those holding the identity. This would shed light on the origins of essentialism-mitigating forms of prejudice.

Future research should also explore how children's own social category membership shapes their endorsement of different causal-explanatory theories. Children essentialize outgroups moreso than ingroups (Essa et al., 2020; Pauker, Ambady, \& Apfelbaum, 2010; Shilo et al., 2019), suggesting that children may also endorse agentic and structural explanations moreso for ingroups than for outgroups. Yet, little is known about how agentic or structural reasoning varies by children's social category membership. Children from marginalized groups are more likely to report experiencing discrimination (see Spears Brown \& Bigler, 2005 for a review), are more aware of stereotypes (McKown \& Weinstein, 2003), and experience more parental socialization about discrimination (Hughes \& Johnson, 2001) than children from nonmarginalized groups. As such, one might expect these children to generate more structural explanations, about their ingroup or even in general. Some troubling evidence, though, reveals the opposite pattern, with children from marginalized groups offering more meritocratic and 
fewer structural explanations for their own group's low status compared to children from nonmarginalized groups (Spears Brown, 2006), and children of incarcerated parents attributing incarceration to personal rather than structural causes, at rates no different from other children (Dunlea \& Heiphetz, 2020). Future research should explore how children's own identities and experiences shape their explanatory reasoning.

Finally, although the present argument focuses on the explanatory component of social essentialism, recall that there are other components of social essentialism (e.g., stability, withingroup similarity) that impact prejudice in their own ways. Future research should consider the multicomponent nature of essentialist, structural, and agentic theories, and how each of these components may shape prejudice. Initial research suggests that different components of prejudice may be differently related to prejudice, necessitating a nuanced and component-specific approach. For example, although viewing criminal behavior as biologically-caused reduces perceptions of blameworthiness, as discussed, it also increases people's punitiveness toward criminal behavior (de Vel-Palumbo, Howarth, \& Brewer, 2019; Kraus \& Keltner, 2013). This may be because the "stability" component of essentialism leads people to reason that the individual is likely to reoffend (Cheung \& Heine, 2015; Martin \& Heiphetz, 2021). As another example, although essentialist views of racial and gender differences promote prejudice relative to structural views, both essentialist and structural views might similarly support stereotypic generalizations about group members' similarity to one another (Vasilyeva \& Lombrozo, 2020). Thus, although this paper focuses just on the causal-explanatory component of essentialism, future research should consider how other components of essentialism shape prejudice relative to other causal-explanatory theories. 


\section{Conclusion}

The social consequences of children's essentialist intuitions are well-discussed, but to date, these discussions have primarily portrayed essentialism as socially pernicious. Here, I review emerging evidence that essentialism can mitigate certain forms of prejudice as well. In doing so, I aim to move research on understudied forms of prejudice from the margins to the center of these discussions, while also leveraging this research to better understand underlying cognitive processes. Although many processes undergird relations between essentialism and prejudice, I propose that causal discounting may play a crucial role in accounting for why essentialism promotes some forms of prejudice while mitigating other forms. By broadening the forms of prejudice under investigation, cognitive developmentalists can shed new light on the mechanisms driving prejudice development while also broadening our potential social impact. 


\section{References}

Ali, N., Schlottmann, A., Shaw, A., Chater, N., \& Oaksford, M. (2010). Causal discounting and conditional reasoning in children. Cognition and conditionals: Probability and logic in human thought, 117-134.

Allport, G. W., Clark, K., \& Pettigrew, T. (1954). The nature of prejudice.

Angermeyer, M. C., \& Matschinger, H. (2004). The stereotype of schizophrenia and its impact on discrimination against people with schizophrenia: results from a representative survey in Germany. Schizophrenia Bulletin, 30(4), 1049.

Baker, M., \& Menken, M. (2001). Time to abandon the term mental illness. British Medical Journal, 322(7291), 937.

Bañales, J., Marchand, A. D., Skinner, O. D., Anyiwo, N., Rowley, S. J., \& Kurtz-Costes, B. (2020). Black adolescents' critical reflection development: Parents' racial socialization and attributions about race achievement gaps. Journal of Research on Adolescence, 30, 403-417.

Bastian, B., \& Haslam, N. (2006). Psychological essentialism and stereotype endorsement. Journal of Experimental Social Psychology, 42(2), 228-235.

Bernstein, M. J., Sacco, D. F., Young, S. G., Hugenberg, K., \& Cook, E. (2010). Being “in” with the in-crowd: The effects of social exclusion and inclusion are enhanced by the perceived essentialism of ingroups and outgroups. Personality and Social Psychology Bulletin, 36(8), 999-1009.

Bigler, R. S., Spears Brown, C., \& Markell, M. (2001). When groups are not created equal: Effects of group status on the formation of intergroup attitudes in children. Child Development, 72(4), 1151-1162. 
Bogart, K. R., Rosa, N. M., \& Slepian, M. L. (2019). Born that way or became that way: Stigma toward congenital versus acquired disability. Group Processes \& Intergroup Relations, $22(4), 594-612$.

Bridgers, S., Buchsbaum, D., Seiver, E., Griffiths, T. L., \& Gopnik, A. (2016). Children's causal inferences from conflicting testimony and observations. Developmental Psychology, $52(1), 9$.

Carvalho, K., Peretz-Lange, R., \& Muentener, P. (2021). Causal Explanations for Weight Influence Children's Social Preferences: Biological-Essentialist Explanations Reduce, and Behavioral Explanations Promote, Preferences for Thin Friends. Child Development.

Chalik, L., Leslie, S. J., \& Rhodes, M. (2017). Cultural context shapes essentialist beliefs about religion. Developmental Psychology, 53(6), 1178

Chalik, L., \& Rhodes, M. (2015). The communication of naïve theories of the social world in parent-child conversation. Journal of Cognition and Development, 16(5), 719-741.

Cheung, B. Y., \& Heine, S. J. (2015). The double-edged sword of genetic accounts of criminality: Causal attributions from genetic ascriptions affect legal decision making. Personality and Social Psychology Bulletin, 41(12), 1723-1738.

Cimpian, A., \& Salomon, E. (2014). The inherence heuristic: An intuitive means of making sense of the world, and a potential precursor to psychological essentialism. Behavioral and Brain Sciences, 37(5), 461

Cimpian, A., \& Steinberg, O. D. (2014). The inherence heuristic across development: Systematic differences between children's and adults' explanations for everyday facts. Cognitive Psychology, 75, 130-154.

Corrigan, P. W. (2000). Mental health stigma as social attribution: Implications for research 
methods and attitude change. Clinical Psychology: Science and Practice, 7(1), 48-67.

Dar-Nimrod, I., \& Heine, S. J. (2011). Genetic essentialism: on the deceptive determinism of DNA. Psychological Bulletin, 137(5), 800.

Dautel, J. B., \& Kinzler, K. D. (2018). Once a French speaker, always a French speaker? Bilingual children's thinking about the stability of language. Cognitive Science, 42, 287 302.

Davey, A. G. (1983). Learning to be prejudiced: Growing up in multi-ethnic Britain. London: Edward Arnold.

Davoodi, T., Soley, G., Harris, P. L., \& Blake, P. R. (2020). Essentialization of social categories across development in two cultures. Child Development, 91(1), 289-306.

Deeb, I., Segall, G., Birnbaum, D., Ben-Eliyahu, A., \& Diesendruck, G. (2011). Seeing isn't believing: the effect of intergroup exposure on children's essentialist beliefs about ethnic categories. Journal of Personality and Social Psychology, 101(6), 1139.

Diedrichs, P. C., \& Barlow, F. K. (2011). How to lose weight bias fast! Evaluating a brief antiweight bias intervention. British Journal of Health Psychology, 16(4), 846-861.

Diesendruck, G., Birnbaum, D., Deeb, I., \& Segall, G. (2013). Learning what is essential: Relative and absolute changes in children's beliefs about the heritability of ethnicity. Journal of Cognition and Development, 14(4), 546-560.

Diesendruck, G., Goldfein-Elbaz, R., Rhodes, M., Gelman, S., \& Neumark, N. (2013). Crosscultural differences in children's beliefs about the objectivity of social categories. Child Development, 84(6), 1906-1917.

Diesendruck, G., \& HaLevi, H. (2006). The role of language, appearance, and culture in children's social category-based induction. Child Development, 77(3), 539-553. 
Diesendruck, G., \& Menahem, R. (2015). Essentialism promotes children's inter-ethnic bias. Frontiers in Psychology, 6, 1180.

Dovidio, J. F., Hewstone, M., Glick, P., Esses, V. (2010). The SAGE handbook of prejudice, stereotyping, and discrimination. SAGE, Thousand Oaks, CA, USA.

Dunham, Y., Newheiser, A. K., Hoosain, L., Merrill, A., \& Olson, K. R. (2014). From a different vantage: Intergroup attitudes among children from low-and intermediate-status racial groups. Social Cognition, 32(1), 1-21.

Dunlea, J. P., \& Heiphetz, L. (2020). Children's and adults' understanding of punishment and the criminal justice system. Journal of Experimental Social Psychology, 87, 103913.

Dunlea, J. P., \& Heiphetz, L. (2020, under review). The Benefits of External Explanations Remain through Thick and Thin: Tests in Punitive and Non-Punitive Contexts.

Erickson, J. E., Keil, F. C., \& Lockhart, K. L. (2010). Sensing the coherence of biology in contrast to psychology: Young children's use of causal relations to distinguish two foundational domains. Child Development, 81(1), 390-409.

Essa, F., Weinsdörfer, A., Shilo, R., Diesendruck, G., \& Rakoczy, H. (2020). Children Explain In-and Outgroup Behavior Differently. Social Development.

Feeney, A., Dautel, J., Phillips, K., Leffers, J., \& Coley, J. (2020). The development of essentialist, ethnic and civic intuitions about national categories. Advances in Child Development and Behavior, 59, 95-131.

Flanagan, C. A., Kim, T., Pykett, A., Finlay, A., Gallay, E. E., \& Pancer, M. (2014). Adolescents' theories about economic inequality: Why are some people poor while others are rich?. Developmental Psychology, 50(11), 2512.

Fugelsang, J. A., \& Thompson, V. A. (2001). Belief-Based and covariation-based cues affect 
causal discounting. Canadian Journal of Experimental Psychology, 55(1), 70.

Gaither, S. E., Schultz, J. R., Pauker, K., Sommers, S. R., Maddox, K. B., \& Ambady, N. (2014). Essentialist thinking predicts decrements in children's memory for racially ambiguous faces. Developmental Psychology, 50(2), 482.

Ganea, P. A., Larsen, N. E., \& Venkadasalam, V. P. (2020). The role of alternative theories and anomalous evidence in children's scientific belief revision. Child Development.

Gelman, S. A. (2003). The essential child: Origins of essentialism in everyday thought. Oxford University Press, USA.

Gelman, S. A., Collman, P., \& Maccoby, E. E. (1986). Inferring properties from categories versus inferring categories from properties: The case of gender. Child Development, 396404.

Gelman, S. A., Heyman, G. D., \& Legare, C. H. (2007). Developmental changes in the coherence of essentialist beliefs about psychological characteristics. Child Development, $78(3), 757-774$

Gelman, S. A., \& Taylor, M. G. (2000). Gender essentialism in cognitive development.

Gelman, S. A., Taylor, M. G., Nguyen, S. P., Leaper, C., \& Bigler, R. S. (2004). Mother-child conversations about gender: Understanding the acquisition of essentialist beliefs. Monographs of the Society for Research in Child Development, i-142.

Gelman, S. A., \& Wellman, H. M. (1991). Insides and essences: Early understandings of the non-obvious. Cognition, 38(3), 213-244.

Goodman, N., Dornbusch, S. M., Richardson, S. A., \& Hastorf, A. H. (1963). Variant reactions to physical disabilities. American Sociological Review, 429-435.

Gopnik, A., Sobel, D. M., Schulz, L. E., \& Glymour, C. (2001). Causal learning mechanisms in 
very young children: two-, three-, and four-year-olds infer causal relations from patterns of variation and covariation. Developmental Psychology, 37(5), 620.

Gopnik, A., Glymour, C., Sobel, D. M., Schulz, L. E., Kushnir, T., \& Danks, D. (2004). A theory of causal learning in children: causal maps and Bayes nets. Psychological Review, $111(1), 3$.

Gülgöz, S., \& Gelman, S. A. (2017). Who's the boss? Concepts of social power across development. Child Development, 88(3), 946-963.

Haslam, N., \& Levy, S. R. (2006). Essentialist beliefs about homosexuality: Structure and implications for prejudice. Personality and Social Psychology Bulletin, 32(4), 471-485.

Haslam, N., Rothschild, L., \& Ernst, D. (2002). Are essentialist beliefs associated with prejudice?. British Journal of Social Psychology, 41(1), 87-100.

Hegarty, P., \& Pratto, F. (2001). Sexual orientation beliefs: Their relationship to anti-gay attitudes and biological determinist arguments. Journal of Homosexuality, 41(1), 121 135.

Heiphetz, L. (2019). Moral essentialism and generosity among children and adults. Journal of Experimental Psychology: General, 148(12), 2077.

Heiphetz, L., Gelman, S. A., \& Young, L. L. (2017). The perceived stability and biological basis of religious beliefs, factual beliefs, and opinions. Journal of Experimental Child Psychology, 156, 82-98.

Hirschfeld, L. A. (2008). Children's developing conceptions of race. Handbook of race, racism, and the developing child, 37-54.

Horn, S. S. (2019). Sexual Orientation and Gender Identity-Based Prejudice. Child Development Perspectives, 13(1), 21-27. 
Horn, S. S., \& Heinze, J. (2011). " She can 't help it, she was born that way": Adolescents beliefs about the origins of homosexuality and sexual prejudice. Anales de Psicología, 27(3).

Horn, S. S. (2006). Heterosexual adolescents' and young adults' beliefs and attitudes about homosexuality and gay and lesbian peers. Cognitive Development, 21(4), 420-440.

Hughes, D., \& Johnson, D. (2001). Correlates in children's experiences of parents' racial socialization behaviors. Journal of Marriage and Family, 63(4), 981-995.

Hussak, L. J., \& Cimpian, A. (2019). “It feels like it's in your body": How children in the United States think about nationality. Journal of Experimental Psychology: General, 148(7), 1153.

Hussak, L. J., \& Cimpian, A. (2015). An early-emerging explanatory heuristic promotes support for the status quo. Journal of Personality and Social Psychology, 109(5), 739.

Jaswal, V. K. (2010). Believing what you're told: Young children's trust in unexpected testimony about the physical world. Cognitive Psychology, 61(3), 248-272.

Jayaratne, T. E., Ybarra, O., Sheldon, J. P., Brown, T. N., Feldbaum, M., Pfeffer, C. A., \& Petty, E. M. (2006). White Americans' genetic lay theories of race differences and sexual orientation: Their relationship with prejudice toward Blacks, and gay men and lesbians. Group Processes \& Intergroup Relations, 9(1), 77-94.

Kelley, H. H. (1971). Attribution in social interaction. In E. E. Jones, D. E. Kanouse, H. H. Kelley, R. E. Nisbett, S. Valins, \& B. Weiner (Eds.), Attribution: Perceiving the causes of behavior (pp. 1-26). Morristown, NJ: General Learning Press.

Kinzler, K. D., \& Dautel, J. B. (2012). Children's essentialist reasoning about language and race. Developmental Science, 15(1), 131-138.

Koroni, M., Garagouni-Areou, F., Roussi-Vergou, C. J., Zafiropoulou, M., \& Piperakis, S. M. 
(2009). The stigmatization of obesity in children. A survey in Greek elementary schools. Appetite, 52(1), 241-244.

Kowalski, K., \& Lo, Y. F. (2001). The influence of perceptual features, ethnic labels, and sociocultural information on the development of ethnic/racial bias in young children. Journal of Cross-Cultural Psychology, 32(4), 444-455.

Kraus, M. W., \& Keltner, D. (2013). Social class rank, essentialism, and punitive judgment. Journal of Personality and Social Psychology, 105(2), 247.

Latner, J. D., \& Stunkard, A. J. (2003). Getting worse: the stigmatization of obese children. Obesity Research, 11(3), 452-456.

Lebowitz, M. S., Rosenthal, J. E., \& Ahn, W. K. (2016). Effects of biological versus psychosocial explanations on stigmatization of children with ADHD. Journal of Attention Disorders, 20(3), 240-250.

Levy, S. R., \& Dweck, C. S. (1999). The impact of children's static versus dynamic conceptions of people on stereotype formation. Child Development, 70(5), 1163-1180.

Mandalaywala, T. M. (2020). Does essentialism lead to racial prejudice? It is not so Black and White. The Development of Social Essentialism, 59, 195.

Mandalaywala, T. M., Amodio, D. M., \& Rhodes, M. (2018). Essentialism promotes racial prejudice by increasing endorsement of social hierarchies. Social Psychological and Personality Science, 9(4), 461-469.

Mandalaywala, T. M., Ranger-Murdock, G., Amodio, D. M., \& Rhodes, M. (2019). The nature and consequences of essentialist beliefs about race in early childhood. Child Development, 90(4), e437-e453.

Mandalaywala, T. M., Tai, C., \& Rhodes, M. (2020). Children's use of race and gender as cues to 
social status. PloS one, 15(6), e0234398.

Martin, J. \& Heiphetz, L. (In press). "Internally Wicked": Investigating How and Why Essentialism Influences Punitiveness and Moral Condemnation. Cognitive Science.

McKown, C., \& Weinstein, R. S. (2003). The development and consequences of stereotype consciousness in middle childhood. Child Development, 74(2), 498-515.

Monterosso, J., Royzman, E. B., \& Schwartz, B. (2005). Explaining away responsibility: Effects of scientific explanation on perceived culpability. Ethics \& Behavior, 15(2), 139-158.

Musher-Eizenman, D. R., Holub, S. C., Miller, A. B., Goldstein, S. E., \& Edwards-Leeper, L. (2004). Body size stigmatization in preschool children: The role of control attributions. Journal of Pediatric Psychology, 29(8), 613-620.

Nesdale, D., \& Flesser, D. (2001). Social identity and the development of children's group attitudes. Child Development, 72(2), 506-517.

Newman, L. S., \& Ruble, D. N. (1992). Do young children use the discounting principle?. Journal of Experimental Social Psychology, 28(6), 572-593.

Olson, K. R., Shutts, K., Kinzler, K. D., \& Weisman, K. G. (2012). Children associate racial groups with wealth: Evidence from South Africa. Child Development, 83(6), 1884-1899.

Pauker, K., Ambady, N., \& Apfelbaum, E. P. (2010). Race salience and essentialist thinking in racial stereotype development. Child Development, 81(6), 1799-1813.

Pauker, K., Xu, Y., Williams, A., \& Biddle, A. M. (2016). Race essentialism and social contextual differences in children's racial stereotyping. Child Development, 87(5), 14091422.

Peretz-Lange, R., Perry, J. \& Muentener, P. (2021). Developmental shifts toward 
structural explanations and interventions for social status disparities. Cognitive Development, 58, 101042.

Puhl, R. M., Schwartz, M. B., \& Brownell, K. D. (2005). Impact of perceived consensus on stereotypes about obese people: a new approach for reducing bias. Health Psychology, $24(5), 517$.

Puhl, R. M., \& Latner, J. D. (2007). Stigma, obesity, and the health of the nation's children. Psychological Bulletin, 133(4), 557.

Rhodes, M., Leslie, S. J., Saunders, K., Dunham, Y., \& Cimpian, A. (2018). How does social essentialism affect the development of inter-group relations?. Developmental Science, 21(1), e12509.

Rhodes, M., Leslie, S. J., \& Tworek, C. M. (2012). Cultural transmission of social essentialism. Proceedings of the National Academy of Sciences, 109(34), 13526-13531.

Rhodes, M., \& Mandalaywala, T. M. (2017). The development and developmental consequences of social essentialism. Wiley Interdisciplinary Reviews: Cognitive Science, 8(4), e1437.

Richardson, S. A., Goodman, N., Hastorf, A. H., \& Dornbusch, S. M. (1961). Cultural uniformity in reaction to physical disabilities. American Sociological Review, 241-247.

Roberts, S. O., \& Gelman, S. A. (2016). Can White children grow up to be Black? Children's reasoning about the stability of emotion and race. Developmental Psychology, 52(6), 887.

Roberts, S. O., Ho, A. K., Rhodes, M., \& Gelman, S. A. (2017). Making boundaries great again: Essentialism and support for boundary-enhancing initiatives. Personality and Social Psychology Bulletin, 43(12), 1643-1658.

Schulz, L. E., Bonawitz, E. B., \& Griffiths, T. L. (2007). Can being scared cause tummy aches? 
Naive theories, ambiguous evidence, and preschoolers' causal inferences. Developmental Psychology, 43(5), 1124.

Segall, G., Birnbaum, D., Deeb, I., \& Diesendruck, G. (2015). The intergenerational transmission of ethnic essentialism: How parents talk counts the most. Developmental Science, 18(4), $543-555$.

Seiver, E., Gopnik, A., \& Goodman, N. D. (2013). Did she jump because she was the big sister or because the trampoline was safe? Causal inference and the development of social attribution. Child Development, 84(2), 443-454.

Shilo, R., Weinsdörfer, A., Rakoczy, H., \& Diesendruck, G. (2019). The out-group homogeneity effect across development: A cross-cultural investigation. Child Development, 90(6), 2104-2117.

Shutts, K., Kinzler, K. D., Katz, R. C., Tredoux, C., \& Spelke, E. S. (2011). Race preferences in children: Insights from South Africa. Developmental Science, 14(6), 1283-1291.

Shutts, K., Brey, E. L., Dornbusch, L. A., Slywotzky, N., \& Olson, K. R. (2016). Children use wealth cues to evaluate others. PloS one, 11(3), e0149360.

Smith, L. A., \& Williams, J. M. (2004). Children's understanding of the causal origins of disability. Journal of Cognition and Development, 5(3), 383-397.

Smyth, K., Feeney, A., Eidson, R. C., \& Coley, J. D. (2017). Development of essentialist thinking about religion categories in Northern Ireland (and the United States). Developmental Psychology, 53(3), 475.

Sobel, D. M., \& Kirkham, N. Z. (2006). Blickets and babies: the development of causal reasoning in toddlers and infants. Developmental Psychology, 42(6), 1103.

Sobel, D. M., \& Kushnir, T. (2013). Knowledge matters: How children evaluate the reliability of 
testimony as a process of rational inference. Psychological Review, 120(4), 779.

Spears Brown, C. (2006). Bias at school: Perceptions of racial/ethnic discrimination among Latino and European American children. Cognitive Development, 21(4), 401-419.

Spears Brown, C., \& Bigler, R. S. (2005). Children's perceptions of discrimination: A developmental model. Child Development, 76(3), 533-553.

Spence, S., Helwig, C. C., \& Cosentino, N. (2018). Children's Judgments and Reasoning About Same-Sex Romantic Relationships. Child Development, 89(3), 988-1003.

Sutherland, S. L., \& Cimpian, A. (2019). Developmental evidence for a link between the inherence bias in explanation and psychological essentialism. Journal of Experimental Child Psychology, 177, 265-281.

Taylor, M. G., Rhodes, M., \& Gelman, S. A. (2009). Boys will be boys; cows will be cows: Children's essentialist reasoning about gender categories and animal species. Child Development, 80(2), 461-481.

Teachman, B. A., Gapinski, K. D., Brownell, K. D., Rawlins, M., \& Jeyaram, S. (2003). Demonstrations of implicit anti-fat bias: the impact of providing causal information and evoking empathy. Health Psychology, 22(1), 68.

Tenney, E. R., Small, J. E., Kondrad, R. L., Jaswal, V. K., \& Spellman, B. A. (2011). Accuracy, confidence, and calibration: How young children and adults assess credibility. Developmental Psychology, 47(4), 1065.

Thomas, A. J., Thomsen, L., Lukowski, A. F., Abramyan, M., \& Sarnecka, B. W. (2018). Toddlers prefer those who win but not when they win by force. Nature Human Behaviour, 2(9), 662-669.

Tiggemann, M., \& Anesbury, T. (2000). Negative stereotyping of obesity in children: The role of 
controllability beliefs. Journal of Applied Social Psychology, 30(9), 1977-1993.

Turiel, E., Hildebrandt, C., Wainryb, C., \& Saltzstein, H. D. (1991). Judging social issues: Difficulties, inconsistencies, and consistencies. Monographs of the Society for Research in Child Development, i-116.

Vasilyeva, N., \& Lombrozo, T. (2020). Structural thinking about social categories: Evidence from formal explanations, generics, and generalization. Cognition, 204, 104383.

de Vel-Palumbo, M., Howarth, L., \& Brewer, M. B. (2019). 'Once a sex offender always a sex offender'? Essentialism and attitudes towards criminal justice policy. Psychology, Crime $\&$ Law, 25(5), 421-439.

Watson, A. C., Otey, E., Westbrook, A. L., Gardner, A. L., Lamb, T. A., Corrigan, P. W., \& Fenton, W. S. (2004). Changing middle schoolers' attitudes about mental illness through education. Schizophrenia Bulletin, 30(3), 563-572.

Whitley Jr, B. E. (1990). The relationship of heterosexuals' attributions for the causes of homosexuality to attitudes toward lesbians and gay men. Personality and Social Psychology Bulletin, 16(2), 369-377.

Williams, M. J., \& Eberhardt, J. L. (2008). Biological conceptions of race and the motivation to cross racial boundaries. Journal of Personality and Social Psychology, 94(6), 1033. 